\title{
Doxycycline-a role in ocular surface repair
}

\author{
V A Smith, S D Cook
}

Br J Ophthalmol 2004;88:619-625. doi: 10.1136/bjo.2003.025551

\begin{abstract}
Background/aims: Doxycycline is a broad spectrum antibiotic that chelates metal ions and is frequently used as part of the treatment of ocular surface diseases. Its therapeutic value has been ascribed to an ability to inhibit matrix metalloproteinase (MMP) activity and both MMP and IL-1 synthesis. The aim of this study was to evaluate the role of doxycycline as an inhibitor of corneal MMPs and assess its contribution to ocular surface repair mechanisms.

Methods: Corneal epithelial cell and keratocyte cultures were grown to confluence and incubated with IL- $1 \alpha$, LPS, doxycycline, or doxycycline and LPS in serum free medium for 4 days. The cells were either harvested and assayed for caspase-3 activity or stained with either AE5 or antivimentin antibodies. Media samples were concentrated and assayed for MMP activity by zymography or using a fluorigenic substrate. ELISA was used to quantify IL-1 $\alpha$, MMPs $-1,-2,-3,-9$, and TIMPs -1 and -2 .

Results: IL- $1 \alpha$ and LPS had no effect on MMP/TIMP production by cultured corneal epithelial cells and keratocytes. Corneal MMP-2 inhibition by doxycycline was partially $\left[\mathrm{Ca}^{2+}\right]$ dependent but irreversible. At the minimum inhibitory concentration, $100 \mu \mathrm{m}$, doxycycline had no apparent effect on MMP and TIMP production, but ultimately caused the death of keratocytes and some of the epithelial cells that detached from their basement membrane. Caspase- 3 activity was not detected in dead or dying keratocytes. The mechanism of cell death in cultured corneal epithelial cells was not caspase- 3 related apoptosis as the activity of this enzyme, normally detectable, was lost. The epithelial cells that survived doxycycline treatment did not bind antivimentin antibody and compared with controls, reacted less with the AE5 antibody. They were probably transient amplifying cells. Conclusions: Doxycycline irreversibly inhibits corneal MMP2 activity by chelating the metal ions that are catalytically and structurally essential. Corneal MMP/TIMP production in vitro is not modulated by IL-1 1 , LPS, or doxycycline. The therapeutic value of doxycycline may depend upon its effective concentration at the ocular surface and probably relates to its chelating properties.
\end{abstract}

$\mathrm{D}$ oxycycline ( $\alpha$-6 deoxy-5-hydroxytetracycline) is a metal ion chelator and a broad spectrum antibiotic that prevents access of acyl t-RNA to the acceptor site on the mRNA-30s ribosomal subunit complex. In this role it is known to be more effective against bacteria than mammalian cells because the former actively transport the compound through their cytoplasmic membranes. No such carrier systems exist on the cytoplasmic membranes of mammalian cells. ${ }^{1}$

In addition to these established functions, other properties that have recently been ascribed to doxycycline include differential inhibition of the activity of members of the matrix metalloproteinase (MMP) family, ${ }^{2-5}$ inhibition of
MMP synthesis, ${ }^{6-9}$ inhibition of interleukin-1 synthesis, ${ }^{10} 11$ inhibition of activated B cell function, ${ }^{12}$ inhibition of nitrous oxide (NO) synthesis by lipopolysaccharide (LPS) activated macrophage, ${ }^{13}$ and inhibition of collagen synthesis by cultured chondrocytes. ${ }^{15}$

Doxycycline is an orally administered drug. With varying degrees of success it has been used to treat patients with rheumatoid arthritis. ${ }^{4}{ }^{16}$ It is also a recommended treatment for patients with ocular surface diseases, particularly recurrent epithelial cell erosion, ${ }^{9}{ }^{17}$ rosacea, ${ }^{18}$ and keratitis sicca. ${ }^{19}$ In the latter cases, successes have been attributed to the inhibition of tear film MMP and interleukin-1 (IL-1) synthesis. ${ }^{3} 20$

The aim of this study is to evaluate the effect of doxycycline on the synthesis and activity of corneal MMPs and their inhibitors (TIMPs) and on the viability of cultured corneal epithelial cells and keratocytes.

\section{METHODS}

\section{Tissue culture}

Normal corneas, which proved to be unsuitable for transplant but were received with research permission, were obtained from the Bristol CTS Eye Bank. All cell cultures were prepared in a class 11 safety cabinet and incubated at $36^{\circ} \mathrm{C}$ under $5 \%$ $\mathrm{CO}_{2}$.

Keratocytes were cultured from central corneal stromal explants placed in $25 \mathrm{ml}$ tissue culture flasks with Dulbecco's MEM medium (Invitrogen, Paisley, UK) containing an antibiotic, antimycotic cocktail (Sigma, Dorset, UK), Lglutamine and foetal calf serum (FCS, $10 \% \mathrm{v} / \mathrm{v}$ ) as described previously. ${ }^{21}$ The cells were trypsinised during the logarithmic phase of growth, aliquoted into 6 well plates and grown to confluence for experimentation.

Epithelial cell cultures were prepared by plating out three $2 \mathrm{~mm}$ diameter explants taken from the anterior limbus region of corneas in each of six well plates wetted with MEM containing $15 \%(\mathrm{v} / \mathrm{v})$ FCS. Once attached, additional growth medium $(2.5 \mathrm{ml})$ was added. The growth medium was replenished every 3-4 days and the cell cultures were used for experimentation when approximately $70 \%$ confluent.

\section{Experimental cell incubation conditions}

Doxycycline is very sparingly soluble in aqueous solution and at concentrations exceeding $300 \mu \mathrm{M}$ it observably precipitates and/or pulls the MEM salts out of solution. For these reasons, stock solutions of solubilised doxycycline were prepared in dimethyl sulphoxide and the growth media solutions, made up to a maximal concentration of $200 \mu \mathrm{M}$ doxycycline, were not filter sterilised after its addition. Both epithelial cell and keratocyte cultures were incubated, minimally in triplicate, in serum free medium or serum free medium containing either

Abbreviations: FCS, fetal calf serum; HRP, horseradish peroxidase; LPS, lipopolysaccharide; MMP, matrix metalloproteinase; PBS, phosphate buffered saline; RFU, relative fluorescence unit 
IL- $1 \alpha(10 \mu \mathrm{g} / \mathrm{ml})$, lipopolysaccharide (LPS ex E coli, Sigma, $10 \mu \mathrm{g} / \mathrm{ml}$ ), doxycycline (Sigma, 0-200 $\mu \mathrm{M}$ ) or a combination of LPS $(10 \mu \mathrm{g} / \mathrm{ml})$ and doxycycline $(100 \mu \mathrm{M})$. After 4 days the media was collected and centrifuged at $1500 \mathrm{rpm}$ for 3 min to pellet detached cells. These were resuspended and counted using a haemocytometer. Small samples of the culture media were retained for zymographic analysis. Ammonium sulphate $(80 \% \mathrm{w} / \mathrm{v})$ was added to the remainders to precipitate the cell secreted proteins. After $16 \mathrm{~h}$ these were collected by centrifugation at $12500 \mathrm{rpm}, 4^{\circ} \mathrm{C}$ and after resuspension in $0.05 \mathrm{M}$ Tris $\mathrm{HCl}, \mathrm{pH} 7.4$, stored at $-80^{\circ} \mathrm{C}$ prior to analysis.

Cell growth and/or respiratory rate measurements Alamar blue (BioSource Europe, SA, Nivelles, Belgium) was added to the cell culture media at a concentration of $5 \%(\mathrm{v} / \mathrm{v})$. The kinetics of its reduction were followed fluorimetrically over $80 \mathrm{~min}$ (excitation $540 \mathrm{~nm}$, emission $590 \mathrm{~nm}$ ).

\section{Protein concentration estimation}

The concentration of the secreted proteins was measured at $280 \mathrm{~nm}$ in 96 well plates using solutions of BSA of known concentration as calibration references.

\section{Apoptosis assays}

Caspase-3 activity was measured in epithelial cells and keratocytes cultured in the absence and presence of doxycycline. After counting with a haemocytometer, the cells pelleted from media samples were combined with the cells that had remained attached to their matrix and required trypsinisation to release them. A fluorimetric (CASP-3-F) assay kit was purchased from Sigma Cell lysates were obtained and assayed for caspase-3 activity as directed.

\section{MMP detection and activity assays}

Substrate polyacrylamide gel electrophoresis

The protocol first described by Unemori and Werb ${ }^{22}$ was followed. As described previously, all samples were applied to the gels without heating or reduction, ${ }^{23}$ at fixed volume (culture media samples) or fixed protein concentration (concentrated protein samples). High molecular weight markers (210 000-25 000; Sigma) were routinely included on each gel.

\section{Using Mca-Pro-Leu-Gly-Leu-Dpa-Ala-Arg- $\mathrm{NH}_{2}$ as substrate}

The Gly-Leu bond of peptides may be cleaved by almost all MMPs. This particular substrate $(40 \mu \mathrm{M})$ was used to investigate the effects of IL- $1 \alpha$, LPS and doxycycline on the activity of the MMPs secreted by cultured corneal epithelial cells and keratocytes because the molar extinction coefficient of the Mca-Pro-Leu product is extremely high at its emission wavelength. The reaction kinetics were followed fluorimetrically (excitation $325 \mathrm{~nm}$, emission $393 \mathrm{~nm}$ ) at $30^{\circ} \mathrm{C}$ in $0.05 \mathrm{M}$ Tris $\mathrm{HCl}$ buffer $\mathrm{pH} 7.6$ containing $0.2 \mathrm{M} \mathrm{NaCl}, 5 \mathrm{mM}$ $\mathrm{CaCl}_{2}$, and $20 \mu \mathrm{M} \mathrm{ZnCl}$.

\section{Western blot immunoanalysis}

For comparative purposes, all samples were of similar protein concentration and were loaded, alongside reference proteins, on $9 \%$ polyacrylamide gels after reduction ( $1 \% \mathrm{v} / \mathrm{v}$ mercaptoethanol) and heating in boiling water for 2 minutes. ${ }^{24}$ After electrophoresis, the separated proteins were electroblotted onto immobilon PDVF membranes (Millipore Ltd Hertfordshire, UK) and probed with either polyclonal rabbit anti MMP-I, anti MMP-9, or anti IL- $1 \alpha$ antibodies, Chemicon, Hampshire, UK). The secondary antibodies were horseraddish peroxidase (HRP) linked and diaminobenzidine was used $(0.075 \% \mathrm{v} / \mathrm{v})$ as substrate to visualise the immunoreactive proteins.

\section{ELISA quantification}

Unless otherwise stated, antihuman polyclonal antibodies raised in rabbit and purchased from Chemicon were used for this investigation. A selection of the MMPs and TIMPs secreted by the cultured corneal epithelial cells and keratocytes were quantified by ELISA. All samples quantified together were of a similar protein concentration (40$100 \mu \mathrm{g}$ ). They were also assayed in triplicate alongside a dilution series of reference protein of known concentration. Each well of a 96 well plate was blocked with phosphate buffered saline (PBS) containing 5\% FCS before sequentially adding the appropriate primary antibody and HRP linked secondary antibody. The plates were extensively washed with TBS/TBS-Tween/TBS-FCS before and after adding the antibodies. Tetramethylbenzidine (Sigma) dissolved in phosphate citrate buffer containing $7.5 \mu \mathrm{H}_{2} \mathrm{O}_{2}$ was used as the HRP substrate. The kinetics of reduction were followed at $370 \mathrm{~nm}, 30^{\circ} \mathrm{C}$.

\section{Immunohistology}

AE5 is an antibody that binds cytokeratin 3 and is used as a marker of corneal epithelial cell differentiation. ${ }^{25}$ Vimentin is a structural protein that is ubiquitously present in fibroblasts but may also be detected in limbal stem cells. Thus AE5 (ICN, Hampshire, UK) and antivimentin (Chemicon) antibodies were used to investigate the phenotypic composition of the cultured epithelial cells. These were fixed in situ using formal saline $(10 \% \mathrm{v} / \mathrm{v})$, permeabilised using Triton X-100 (0.25\% in PBS) then sequentially incubated with either the AE5 or antivimentin antibodies, diluted 1:500 and the appropriate fluorescent secondary antibody diluted 1:100 for 1 hour at $37^{\circ} \mathrm{C}$. After incubating with antibody, the cultures were washed three times with PBS containing Tween $20(0.1 \%)$. The cultures were photographed using a digital camera mounted on a fluorescent microscope.

\section{RESULTS}

\section{Effect of doxycycline on MMP-2 activity}

In initial experiments corneal MMP-2 activity was measured in the presence of doxycycline $(0-200 \mu \mathrm{M})$ using the quenched fluorescent peptide as substrate. The results obtained (table 1) indicated that the activity of this enzyme was not inhibited at concentrations below $20 \mu \mathrm{M}$ and because doxycycline is yellow, the observed activity inhibition at the higher concentrations could have resulted from colour quenching. The zymographic MMP-2 activity data did not support this possibility. Furthermore, as MMP activity is $\mathrm{Ca}^{2+}$ dependent and it was subsequently shown that the inhibitory effects of doxycycline were attenuated by the inclusion of excess $\mathrm{Ca}^{2+}$ in the assay buffer (fig 1), metal ion chelation is the most likely mechanism of doxycycline inhibition.

Additional experiments in which doxycycline $(0-200 \mu \mathrm{M})$ was included in the culture medium of corneal epithelial cells and keratocytes again indicated that the measurable activity

\begin{tabular}{|c|c|}
\hline Doxycycline $(\mu \mathrm{M})$ & Corneal MMP-2 activity (RFU/sec) \\
\hline 0.0 & $32.0(1.8)$ \\
\hline 1.0 & $35.9(2.2)$ \\
\hline 20.0 & $34.6(1.8)$ \\
\hline 100.0 & $21.2(1.0)$ \\
\hline 1000.0 & $6.0(0.3)$ \\
\hline
\end{tabular}



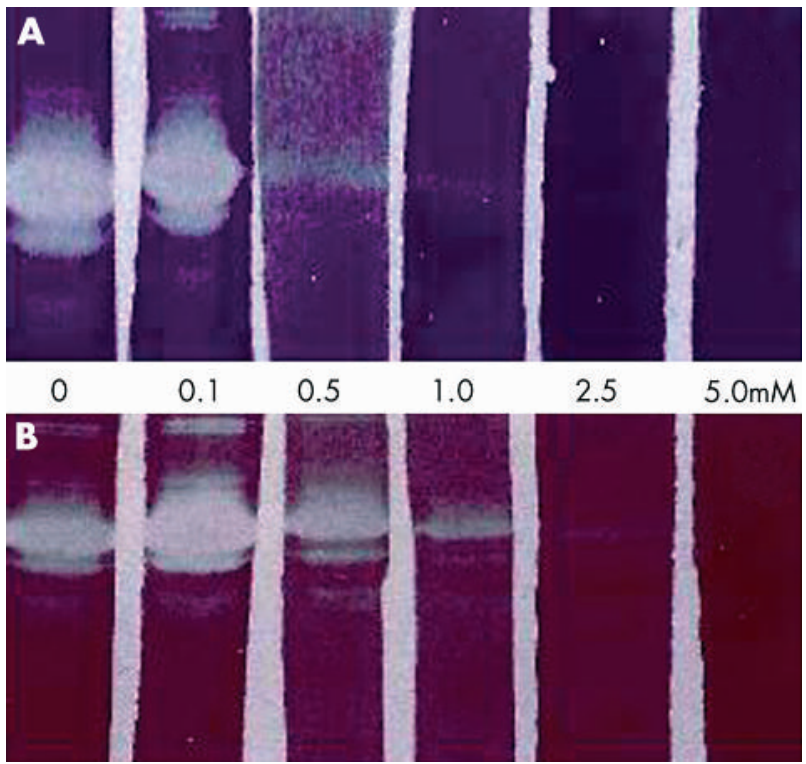

\section{1}
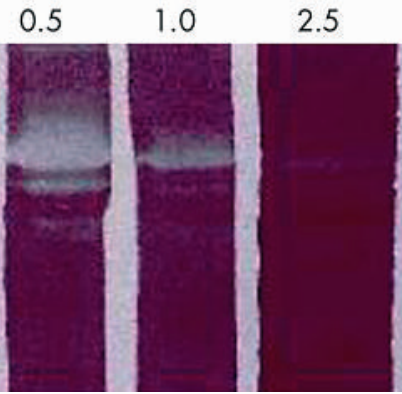

$5.0 \mathrm{mM}$

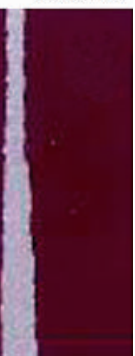

Figure 1 Effect of doxycycline on the zymographic activity profile of corneal MMP-2 when included at varying concentration in incubation buffer containing $2 \mathrm{mM} \mathrm{Ca}^{2+}(\mathrm{A})$ or $10 \mathrm{mM} \mathrm{Ca}^{2+}(\mathrm{B})$.

of the secreted MMPs, assayed with the quenched fluorescent peptide substrate, was reduced by doxycycline only at concentrations exceeding $50 \mu \mathrm{M}$ (data not shown). However, except in the case of the keratocytes incubated with $200 \mu \mathrm{M}$ doxycycline, it was apparent from the zymographic activity profiles (fig 2 ) that the compound effected the appearance of the $62000 M_{r}$ species of MMP-2 and also that the observed reduction in activity was not a result of suppressed enzyme synthesis.

Effect of doxycycline on MMP and TIMP synthesis in cultured corneal epithelial cells and keratocytes

The zymographic MMP-2 activity data suggested that doyxcycline, at concentrations not exceeding $100 \mu \mathrm{M}$, had little effect on MMP-2 production. To confirm this and determine the overall effect of the compound on corneal MMP and TIMP synthesis, the epithelial cell and keratocyte secreted proteins were quantitatively assayed for MMP-1, MMP-2, MMP-3, MMP-9, TIMP-1, and TIMP-2. The experimental data obtained (table 2) provided no evidence that doxycycline selectively or otherwise inhibited MMP and TIMP synthesis. MMP-3 was either absent or present at very low concentrations in both epithelial cell or keratocyte protein samples. Additionally, because the ELISA estimates of the concentrations of MMP-1 in the samples of epithelial cell secreted protein and MMP-1 and MMP-9 in the samples of keratocyte secreted protein were low, and because western

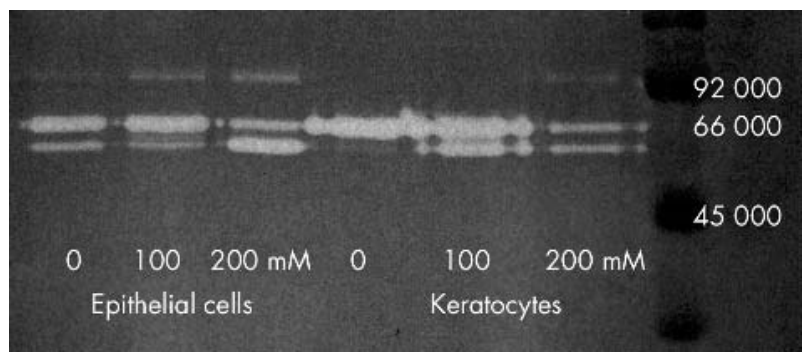

Figure 2 Effect of doxycycline on the zymographic activity profile of MMP-2 secreted by cultured corneal epithelial cells and keratocytes.
Table 2 Effect of doxycycline on MMP and TIMP synthesis in corneal cell cultures

\begin{tabular}{llllll}
\hline $\begin{array}{l}\text { Doxycycline } \\
(\mu \mathrm{M})\end{array}$ & MMP-1 & MMP-2 & $\begin{array}{l}\text { MMP-9 } \\
(\mathrm{pmol} / \mathrm{mg})\end{array}$ & TIMP-1 & TIMP-2 \\
\hline $\begin{array}{l}\text { Epithelial } \\
\text { cells* } \\
0\end{array}$ & $8.2(0.8)$ & $92.0(25.2)$ & $53.7(14.3)$ & 98.2 & 227.8 \\
100 & $7.7(0.6)$ & $87.7(27.8)$ & $51.3(19.9)$ & 108.0 & 226.5 \\
& & & & $(10.8)$ & $(19.1)$ \\
200 & $5.8(1.6)$ & $79.0(28.9)$ & $41.6(12.8)$ & 98.0 & 192.0 \\
& & & & $(38.0)$ & $(25.4)$ \\
Keratocytes* & & & & 131.2 & 202.0 \\
0 & $8.3(1.9)$ & $97.2(20.2)$ & $<2.0$ & $(18.1)$ & $(20.7)$ \\
100 & $7.6(1.4)$ & $80.8(9.4)$ & $<2.0$ & 122.3 & 205.0 \\
& & & & $(15.0)$ & $(25.2)$ \\
\hline
\end{tabular}

blots of the keratocyte secreted proteins probed with anti MMP-1 and anti MMP-9 antibody picked up many high molecular weight proteins but none corresponding to MMP-1 and MMP-9 reference proteins (data not shown), the existence of these proteins in the samples is also questionable.

Although doxycycline does not appear to inhibit MMP synthesis directly, a number of reports have suggested that doxycycline may inhibit MMP synthesis as an indirect consequence of inhibiting IL- $1 \alpha$ synthesis. ${ }^{10}{ }^{11}$ Thus experiments were carried out to determine whether IL- $1 \alpha$, added to
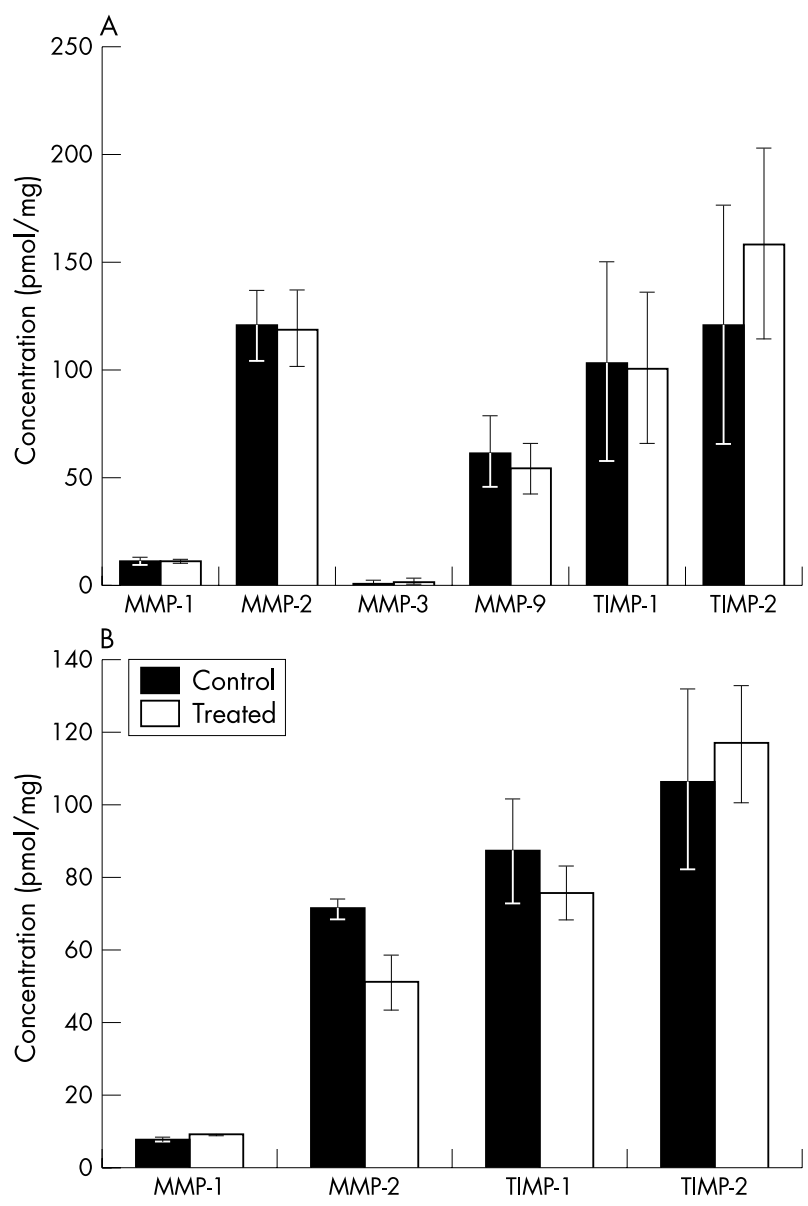

Figure 3 Effect of IL-1 $\alpha$ on cultured corneal epithelial cell (A) and keratocyte (B) MMP and TIMP production. 
the culture medium of corneal epithelial cells and keratocytes, upregulated MMP or TIMP synthesis. The data presented in fig 3, pertaining to a series of experiments in which the concentration of exogenous IL- $1 \alpha$ was $10 \mu \mathrm{M}$, indicated that this was not the case; similar results were also obtained at a 10-fold higher concentration of the cytokine.

Whereas LPS may stimulate the production of proinflammatory cytokines including IL-1, doxycycline apparently inhibits their synthesis. ${ }^{26}$ Thus, further experiments were carried out to determine whether IL- $1 \alpha$ could be detected in the culture medium of corneal epithelial cells and keratocytes incubated in the presence or absence of lipopolysaccharide (LPS, $10 \mu \mathrm{g} / \mathrm{ml}$ ) and/or doxycycline (120 $\mu \mathrm{M})$ for 4 days and secondly whether these treatments modulated MMP and TIMP synthesis. Neither IL- $1 \alpha$ quantification by ELISA (detection limit $45 \mathrm{pmol} / \mathrm{mg}$ ) or western blot immunoanalysis of the concentrated culture media samples (data not shown) provided positive evidence that this cytokine was secreted by the cultured corneal epithelial cells or keratocytes in response to treatment with LPS. Although the LPS and doxycycline also had no effect on the quantity of MMP-1, -2, -3 , and -9 and TIMP- 1 and -2 recovered in the samples of epithelial cell secreted protein, this was not the case for the samples of keratocyte secreted protein. However, although doxycycline did cause a significant reduction in the MMP and TIMP content of these samples (fig 4), this was considered to be a consequence of cytotoxicity.

\section{Toxic effects of doxycycline on epithelial cells and keratocytes \\ Effect of doxycycline on cell viability}

Although the concentration of doxycycline required to significantly inhibit MMP-2 activity $(100 \mu \mathrm{M})$ was apparently insufficient to inhibit MMP synthesis in vitro, after three or four days of incubation with the compound, it became apparent that around this concentration doxycycline
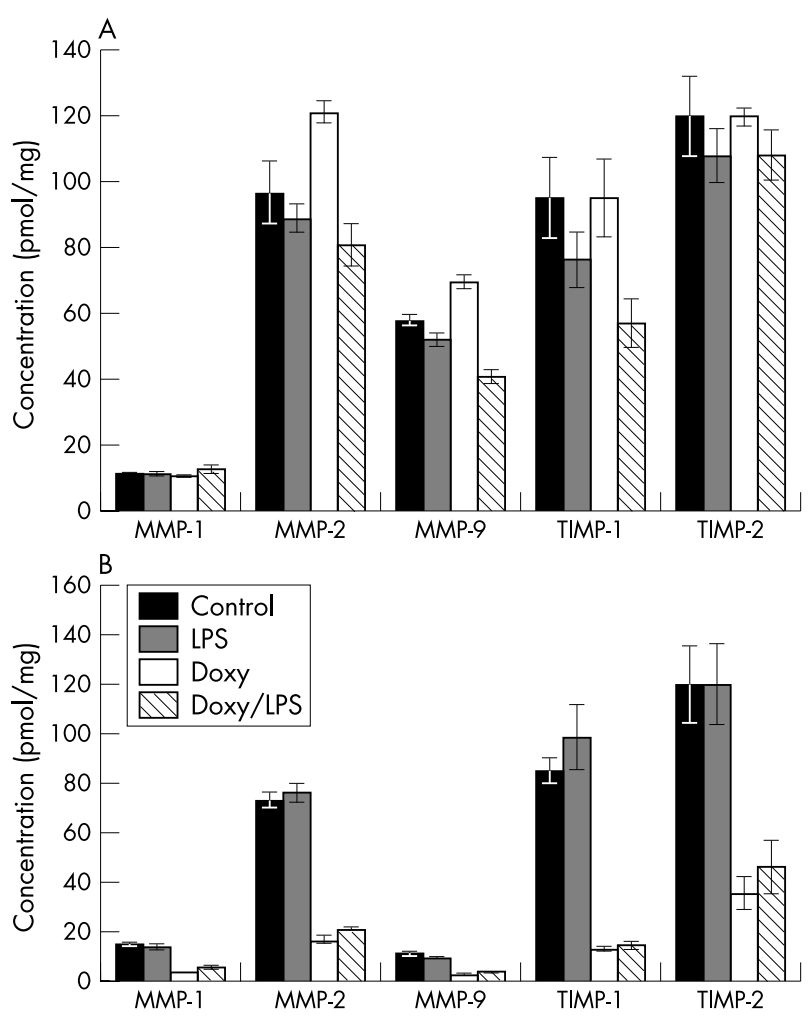

Figure 4 Effect of doxycycline and LPS on MMP and TIMP secretion by corneal epithelial cells (A) and keratocytes (B). affected the cells, particularly the keratocytes (fig 5). In subsequent experiments the rate of alamar blue reduction, usually used as a method of determining viable cell number, was measured before and after a 4 day incubation with/ without doxycycline $(120 \mu \mathrm{M})$ and/or LPS $(10 \mu \mathrm{M})$. The data from these experiments, shown in table 3 , confirmed that doxycycline added at a concentration of $120 \mu \mathrm{M}$ killed keratocytes. At this concentration, it also effected the detachment of (some) of the cultured epithelial cells but given that the rate of alamar blue reduction actually increased in these cultures, the cells were not apparently dead or dying.

\section{Caspase- 3 activity assays}

The results of assaying the cultured keratocytes and epithelial cells and for caspase-3 activity after incubation with doxycycline are given in table 4 . In all keratocyte samples the activity of this enzyme was on the limits of detection. By contrast, the observation that caspase-3 activity was highest in the population of epithelial cells that had not been exposed to doxycycline indicated that the caspase-3 apoptotic pathway is the mechanism by which corneal epithelial cells are normally turned over in culture, but it is not induced or enhanced by doxycycline. Furthermore, the doxycycline concentration dependent reduction in caspase-3 activity probably indicates that for both epithelial cells and keratocytes, the compound initiates cell death by inhibiting protein synthesis in toto.

Immunohistological investigation of cell cultures treated with doxycycline and LPS

Despite being expanded from limbal explants, the corneal epithelial cultures contained two visually distinguishable types of cell. The smaller of these were considered to be the basal cells or transient amplifying cells (TACS) and the larger cells the superficial wing cells. Although LPS had no apparent effect upon the morphological appearance of the epithelial cell cultures, the majority of the cells that remained matrix bound after doxycycline treatment were of the smaller variety. Negative results were obtained after probing control epithelial cell cultures or those treated with doxycycline and/ or LPS with antivimentin antibody and the lack of fluorescent cells indicated that the cultures neither contained putative stem cells nor were contaminated with keratocytes. By contrast, after probing with AE5 fluorescent images of the epithelial cells were observed but compared with the control or LPS treated cultures, there was a marked reduction in the fluorescence intensity of those that had been treated with doxycycline and remained matrix bound (fig 6). This observation provides further evidence that doxycycline treatment has no effect on basal cells but induces the detachment of the more highly differentiated epithelial cells.

\section{DISCUSSION}

Doxycycline is an effective metal ion chelator and not surprisingly therefore, inhibits MMP activity. Claims have been made that doxycycline also inhibits the synthesis of these proteases and that this is an indirect consequence of inhibiting the synthesis/secretion of the proinflammatory cytokine IL-.$^{10112728}$ Thus, in an investigation of the antiinflammatory properties of doxycycline, the effect of this compound on MMP activity and the interrelation between IL$1 \alpha$ and corneal MMP/TIMP systems were examined.

MMP-2 is the major MMP secreted by corneal keratocytes. Partially activated preparations of this enzyme, visualised by zymography and assayed using a quenched fluorescent peptide as substrate, were used to determine the inhibitory concentration range of doxycycline. The results obtained indicated that a minimum concentration of $50 \mu \mathrm{M}$ was 

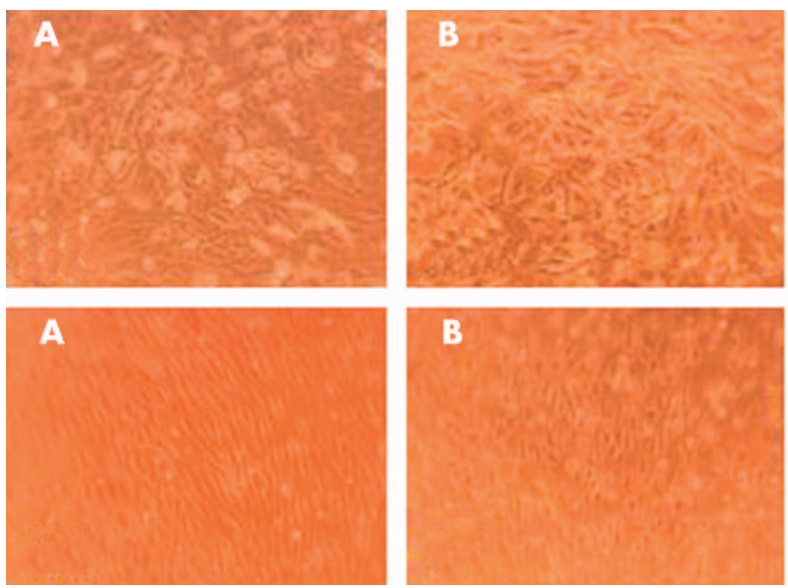

required to detect activity inhibition in the presence of $5 \mathrm{mM}$ $\mathrm{Ca}^{2+}$. Given that the role of this metal ion is to hold the enzyme in its catalytically active conformation and that the $\mathrm{Ca}^{2+}$ dependence of corneal MMP-2 is reversible, the further observation that this could be attenuated by increasing the concentration of exogenous $\mathrm{Ca}^{2+}$ was compatible with the fact that doxycycline is a chelating agent. Similar inhibition kinetics were however observed when the activity of the MMP-2, recovered from the media of keratocytes incubated with doxycycline $(0-200 \mu \mathrm{M})$, was assayed. The results of these experiments showed that the activity inhibition was neither reversible on removal of doxycycline nor related to a reduction in the quantity of MMP-2 secreted. It was therefore considered likely that doxycycline partially extracted the tightly bound catalytic zinc ion from the active site of the protein. This is known to be an irreversible process for, after treating corneal MMP-2 with the zinc ion chelator phenanthroline, activity cannot be restored with exogenous $\mathrm{Zn}^{2+} .2129$

Zymographically MMP-2 presents in two forms, one of $M_{r}$ 66000 , believed to be the inactive or latent form of the enzyme, ${ }^{30}$ the other of $M_{r} 62000$. The proportion of the latter is significantly increased by adding doxycycline to the culture medium of either keratocytes or epithelial cells and may visually account for the reduction in MMP-2 activity assayed directly with the quenched fluorescent peptide substrate: Though the $M_{r} 62000$ species of MMP-2 has been considered to be the activated form of MMP-2, ${ }^{31}{ }^{32}$ we have previously shown that it differs from the $M_{r} 66000$ species only in conformation. Moreover $\mathrm{Ca}^{2+}$ depletion, which would result from doxycycline treatment, favours the $M_{r} 62000$ species, which may be the conformer cleaved to generate activated enzyme but is actually of lower specific activity than that of the $M_{r} 66000$ species. $^{33}$

Some MMPs are inducible enzymes ${ }^{34}$ and can be pathologically activated. As examples MMP-1 is abnormally

Table 3 Effect of doxycycline on the rates of alamar blue reduction by cultured epithelial cells and keratocytes $(n=6)$

\begin{tabular}{|c|c|c|c|}
\hline \multirow[b]{3}{*}{ Culture conditions } & \multicolumn{3}{|c|}{ Rate of alamar blue reduction (RFU/min) } \\
\hline & \multicolumn{2}{|c|}{ Epithelial cells } & \multirow{2}{*}{$\begin{array}{l}\text { Keratocytes } \\
\text { Day } 4\end{array}$} \\
\hline & Day 1 & Day 4 & \\
\hline Control & $0.9(0.3)$ & $1.1(0.1)$ & $4.8(0.4)$ \\
\hline+ LPS $\left(10 \mu \mathrm{g} \mathrm{ml}^{-1}\right)$ & $0.9(0.2)$ & $0.9(0.2)$ & $5.1(0.4)$ \\
\hline + Doxycycline (120 $\mu \mathrm{m})$ & $0.9(0.3)$ & $1.5(0.4)$ & $1.6(0.1)$ \\
\hline + Doxycycline + LPS & $0.8(0.2)$ & $1.6(0.4)$ & $1.3(0.1)$ \\
\hline
\end{tabular}

RFU, relative fluorescence units; LPS, lipopolysaccharide.

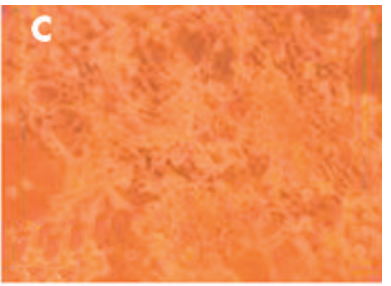

Figure 5 Effect of doxycycline on the morphological appearance of cultured epithelial cells (top row) and keratocytes (bottom row) $\mathrm{A}=0, \mathrm{~B}=100 \mu \mathrm{M}$, $\mathrm{C}=200 \mu \mathrm{M}$.

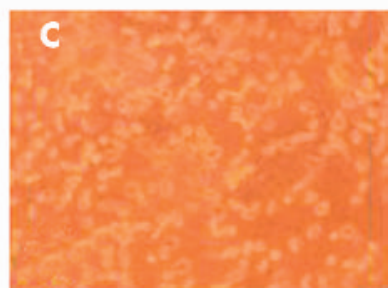

found in corneas of patients with rheumatoid peripheral ulcerative keratitis $^{3637}$ and in corneas with chemical or thermal burns. ${ }^{38}{ }^{39}$ The regulatory agents are growth factors and cytokines. Doxycycline, in addition to inhibiting MMP activity apparently inhibits MMP synthesis and the synthesis of proinflammatory cytokines, particularly IL-1, which may induce the synthesis of MMP-9 in cultured corneal epithelial cells and MMP-1, -3 , and -9 in cultured keratocytes. ${ }^{104041}$ Thus, to investigate the direct effect of doxycycline on MMP and TIMP synthesis and on the IL- $1 \alpha$ dependent MMP and TIMP synthesis in cultured corneal epithelial cells and keratocytes, the quantities of MMP-1, MMP-2, MMP-3, MMP-9, TIMP-1, and TIMP-2, secreted by these cells over a fixed time period, were determined. In these experiments it was shown that the epithelial cell protein preparations contained MMP-2 and MMP-9 but little or no MMP-3 and MMP-1, and the keratocyte protein preparations contained MMP-2 which is constitutively produced in vivo and in vitro and little or no MMP-3, MMP-1, and MMP-9. It was also shown that doxycycline, included in the culture medium of corneal epithelial cells and keratocytes in the concentration range $0-100 \mu \mathrm{M}$, did not significantly inhibit the synthesis of MMP-9 and/or MMP-2 respectively. These findings were contrary to expectation in view of a previous report ${ }^{10}$ that doxycycline inhibits MMP-9 synthesis at a concentration of only $20 \mu \mathrm{M}$, but does not prevent MMP-3 from cleaving and activating corneal epithelial cell MMP-9 at a concentration of $200 \mu \mathrm{M}$.

Furthermore, in the subsequent experiments in which IL$1 \alpha$ was added to culture medium at a concentration of either $10 \mu \mathrm{M}$ or $100 \mu \mathrm{M}$ with or without doxycycline $(100 \mu \mathrm{M})$ the cytokine neither upregulated or induced MMP-1, MMP-2, MMP-3, or MMP-9 synthesis in keratocytes or corneal

Table 4 Caspase- 3 activity of corneal epithelial cells and keratocytes treated with doxycycline

\begin{tabular}{|c|c|c|c|}
\hline \multirow[b]{3}{*}{ Sample } & \multicolumn{3}{|c|}{ Caspase-3 activity (RFU/sec) } \\
\hline & \multicolumn{3}{|c|}{ Doxycycline $(\mu \mathrm{M})$} \\
\hline & 0 & 100 & 200 \\
\hline Epithelial cells $(E)^{*}$ & $0.46(0.02)$ & $0.36(0.04)$ & $0.12(0.02)$ \\
\hline$E+$ caspase & $2.00(0.02)$ & $1.81(0.00)$ & $1.23(0.02)$ \\
\hline$E+$ caspase inhibitor & 0.01 & 0.01 & 0.01 \\
\hline Caspase & 1.30 & - & - \\
\hline Keratocytes $(\mathrm{K}) \dagger$ & 0.02 & 0.01 & 0.01 \\
\hline $\mathrm{K}+$ caspase & 0.01 & 0.01 & 0.01 \\
\hline
\end{tabular}

*Approx $2 \times 10^{5}$ cells/assay; tapprox $5 \times 10^{5}$ cells/assay. RFU, relative fluorescence units. 

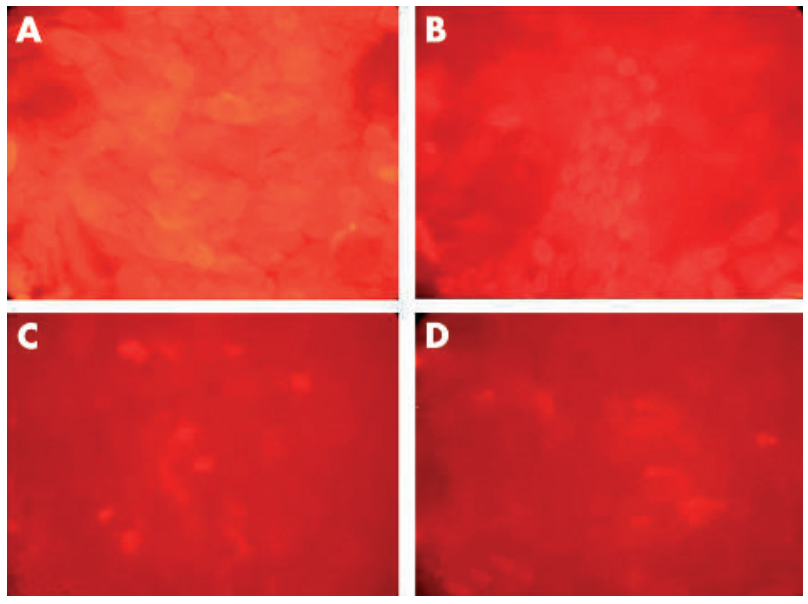

Figure 6 Immunostained epithelial cell cultures. (A) Control; (B) cultured with doxycycline (120 $\mu \mathrm{M})$, immunostained with AE5 antibody; (C) cultured with doxycycline (120 $\mu \mathrm{M})$, immunostained with antivimentin antibody; (D) control, primary antibody omitted.

epithelial cells and no inhibitory effects of doxycycline on the activity of these enzymes were noted.

LPS may stimulate IL- $1 \alpha$ synthesis in inflammatory cells and also in corneal epithelial cells and keratocytes. In these cells the intracellular IL- 1 is apparently present in the mature form whereas the precursor form predominates in their growth medium..$^{10}$ To test the possibility that it is LPS induced intracellular IL-1 that in turn induces MMP synthesis, the concentrations of the MMPs, TIMPs, and IL- $1 \alpha$ secreted by corneal epithelial cells and keratocytes incubated with LPS and/or doxycycline were also compared. These data also indicated that neither LPS nor doxycycline affected the quantities of MMP and TIMP recovered and, if present, the quantities of secreted IL- $1 \alpha$ were also very low. In the absence of any supportive evidence therefore, it was concluded that doxycycline, directly or indirectly, does not inhibit MMP synthesis at the minimum concentration required to inhibit corneal MMP-2 activity (100 $\mu \mathrm{M})$.

Although doxycycline $(100 \mu \mathrm{M})$ did not inhibit MMP production when included in the growth medium of corneal epithelial cells or keratocytes, after 3-4 days, morphological changes in the cultured cells became apparent and significant numbers of the epithelial cells in particular, lifted from their matrix. Though not apparently dead, these cells appeared to be differentiated epithelial cells (wing cells) that reacted strongly with the AE5 antibody. A plausible explanation for their detachment was that doxycycline, acting as a chelating agent, abstracted the $\mathrm{Ca} 2+$ from hemidesmosomes and other Ca2+ dependent junctional proteins. At concentrations exceeding $100 \mu \mathrm{M}$, doxycycline caused cell death, but not, apparently, by the caspase-3 linked apoptotic mechanism as the activity of this enzyme, generally detectable in extracts of cultured epithelial cells was lost rather than increased. The keratocyte cultures were significantly more sensitive than the epithelial cell cultures and the apparent inhibition of MMP-2 production observed at $200 \mu \mathrm{M}$ doxycycline was simply a consequence of its cytotoxicity.

In conclusion, it has been shown that the minimum concentration of doxycycline required to inhibit the activities of corneal MMPs $(100 \mu \mathrm{M})$ is similar to that required to inhibit these enzymes in other tissues. If this concentration is achievable in the tears of patients treated systemically for ocular surface disorders then, in addition to inhibiting MMPs that have been pathologically activated, it may kill migratory keratocytes or fibroblasts responsible for the formation of scar tissue, promote complete coverage of the ocular surface with epithelial basal cells and consequentially the development of a stable, stratified epithelium. Clinical reports suggest that doxycycline is most effective in the treatment of inflammatory ocular conditions. The results presented in this paper, though not supporting a hypothesis that the mechanism is inhibition of IL-1 synthesis in corneal epithelial cells, do not preclude the possibility that doxycycline either kills cells of the immune system or inhibits the synthesis/release of their cytokines and MMPs.

\section{ACKNOWLEDGEMENTS}

We thank the National Eye Research Centre for financial support.

\section{Authors' affiliations}

V A Smith, S D Cook, Division of Ophthalmology, University of Bristol, Bristol, UK

Correspondence to: Dr V A Smith, University of Bristol, Division of Ophthalmology, Lower Maudlin Street, Bristol BS1 2LX, UK;

Val.Smith@bristol.ac.uk

Accepted for publication: 4 October 2003

\section{REFERENCES}

1 Carlini G. Bacteriological and clinical investigations of the activity of a new antibiotic, doxycycline. In: Proceedings of the 5th International Congress of Chemotherapy, Vienna. 1967:457-72.

2 Smith GN, Mickler EA, Hasty KA, et al. Specificity of inhibition of matrix metalloproteinase activity by doxycycline: Relationship to structure of the enzyme. Arthritis Rheum 1999;42:1140-6.

3 Ryan ME, Usman A, Ramamurthy NS, et al. Excessive matrix metalloproteinase activity in diabetes: Inhibition by tetracycline analogues with zinc reactivity. Curr Med Chem 2001;8:305-16.

4 Nordstrom D, Lindy O, Lauhio A, et al. Anti-collagenolytic mechanism of action of action of doxycycline treatment in rheumatoid arthritis. Rheumatol Int 1998;17:175-80.

5 Golub LM, Sorsa T, Lee HM, et al. Doxycycline inhibits neutrophil (PMN)-type matrix metalloproteinases in human adult periodontitis. J Clin Peridontol 1995;22:100-9.

6 Boyle JR, McDermott E, Crowther M, et al. Doxycycline inhibits elastin degradation and reduces metalloproteinase activity in a model of aneurysmal disease. J Vasc Surg 1998;27:354-61.

7 Hanemaaijer R, Sorsa T, Konttinen YT, et al. Matrix metalloproteinase- 8 is expressed in rheumatoid synovial fibroblasts and endothelial cells: Regulation by tumor necrosis factor-alpha and doxycycline. J Biol Chem 1997; 272:31504-9.

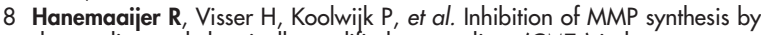
doxycycline and chemically modified tetracyclines (CMTs) in human endothelial cells. Adv Dent Res 1998;12:114-18.

9 Durson D, Kim MC, Solomon A, et al. Treatment of recalcitrant recurrent corneal erosions with inhibitors of matrix metalloproteinase -9 , doxycycline and corticosteroids. Am J Ophthalmol 2001;132:8-13.

10 Solomon A, Rosenblatt M, Li D-Q, et al. Doxycycline inhibition of interleukin-1 in the corneal epithelium. Invest. Ophthalmol \& Vis Sci 2000;41:2544-57.

11 Shlopov BV, Stuart JM, Gumanovskaya ML, et al. Regulation of cartilage collagenase by doxycycline. J Rheumatol $2001 ; 28: 835-42$.

12 Kuzin II, Snyder JE, Ugine GD, et al. Tetracyclines inhibit activated B cell function. Int Immunol 2001;13:921-31.

13 Amin AR, Patel RN, Thakker GD, et al. Post-transcriptional regulation of inducible nitric oxide synthase mRNA in murine macrophages by doxycycline and chemically modified tetracycline. FEBS Letters 1997;410:259-64.

14 D'Agostino P, Arcoleo F, Barbera C, et al. Tetracycline inhibits the nitric oxide synthase activity induced by endotoxin cultured murin macrophages. Eur J Pharmacol 1998;346:283-90.

15 Beekman B, Verzijl N, de Roos JADM, et al. Doxycycline inhibits collagen synthesis by bovine chondrocytes cultured in alginate. Biochem Biophys Res Com 1997;23:107-10.

16 Van der Laan, Molenaar E, Ronday K, et al. Lack of effect of doxycycline on disease activity and joint damage in patients with rheumatoid arthritis. A double blind, placebo controlled trial. J Rheumatol 2001;28:1967-74.

17 Hope-Ross MW, Chell PB, Kervick GN, et al. Oral tetracycline in the treatment of recurrent corneal erosions. Eye 1994:8:384-8.

18 Frucht-Pery J, Sagi E, Hemo I, et al. Efficacy of doxycycline and tetracycline in ocular rosacea. Am J Ophthalmol 1993;1 16:88-92.

19 Culbertson WW, Huang AJ, Mandelbaum SH, et al. Effective treatment of phlyctekeratoconjunctivitis with oral tetracycline. Ophthalmology 1993;100:1358-66.

20 Afonso A, Sobrin L, Monroy DC, et al. Tear fluid Gelatinase B correlates with $\| l-1 \alpha$ concentration and fluorescein clearance in ocular rosacea. Invest Ophthalmol Vis Sci 1999;40:2506-12.

21 Smith VA, Hoh HB, Easty DL. The role of ocular matrix-metalloproteinases in peripheral ulcerative keratitis. Br J Ophthalmol 1999;83:1376-83. 
22 Unemori EN, Werb Z. Reorganisation of polymerised actin: A possible trigger for induction of procollagenase in fibroblasts cultured in and on collagen gels. J Cell Biol 1986;103:1021-31.

23 Smith VA, Rishmawi $\mathrm{H}$, Hussein $\mathrm{H}$, et al. Tear film matrix metalloproteinases and ocular disease. Br J Ophthalmol 2001;85:147-53.

24 Laemmli UK. Cleavage of structural proteins duringthe assembly of the head of bacteriophage T4. Nature 1970;227:680-5.

25 Schermer A, Galvin S, Sun T-T. Differentiation related expression of a major $64 \mathrm{~K}$ corneal keratin in vivo and in culture suggests limbal location of cornea epithelial stem cells. J Cell Biol 1986; 103:49-62

26 Shapira L, Soskolne WA, Houri Y, et al. Protection against endotoxic shock and lipopolysaccharide induced local inflammation by tetracycline: Correlation with inhibition of cytokine secretion. Infect Immun 1996:64:825-8.

27 MacNaul KL, Chartrain N, Lark M, et al. Discoordinate expression of stromelysin, collagenase and tissue inhibitor of metalloproteinase- 1 in rheumatoid human synovial fibroblasts: synergistic effects of interleukin-1 and tumor necrosis factor-alpha on stromelysin expression. J Biol Chem 1990;265:17238-45.

28 Rawdanowicz TJ, Hampton AL, Nagase H, et al. Matrix metalloproteinase production by cultured human endometrial stromal cells: Identification of interstitial collagenase, gelatinase $A$, gelatinase $B$ and stromelysin and their differential regulation by interleukin-1 alpha and tumor necrosis factor-alpha. $J$ Clin Endocrinol Metab 1994;79:530-6.

29 Hoh HB. Ph D Thesis, University of Bristol 1998.

30 Collier JE, Wilhelm SM, Eizen AZ, et al. H-ras oncogene-transformed bronchial epithelial cells (TB-1) secrete a single metalloproteinase capable of degrading basement membrane collagen. J Biol Chem 1988;263:6579-87.
31 Goldberg GI, Marmer BL, Grant GA, et al. Human 72 kilodalton type IV collagenase forms a complex with tissue inhibitor of metalloproteinases designated TIMP-2. Proc Natl Acad Sci 1989;86:8207-11.

32 Howard EW, Bullen EC, Banda MJ. Regulation of the autoactivation of human $72 \mathrm{kDa}$ progelatinase by tissue inhibitor of metalloproteinases-2. J Biol Chem 1991;266:13064-9.

33 Smith VA, Easty DL. Matrix metalloproteinase-2: Involvement in keratoconus. Eu J Ophthalmol 2000;10:215-26.

34 Circolo A, Welgus HG, Pierce GF, et al. Differential regulation of the expression of proteinases/antiproteinases in fibroblasts. Effects of interleukin1 and platelet-derived growth factor. J Biol Chem 1991;226:12283-8.

35 Fabuni RP, Baker AH, Murray EJ, et al. Divergent regulation by cytokines and growth factors of $95 \mathrm{kDa}$ and $72 \mathrm{kDa}$ gelatinases and tissue inhibitors of metalloproteinases $-1,-2$, and -3 in rabbit aortic smooth muscle cells. Biochem J 1996;315:335-42.

36 Riley GP, Harrall RL, Watson PG, et al. Collagenase MMP-1) and TIMP-1 in destructive corneal disease associated with rheumatoid arthritis. Eye 1995;9:703-18.

37 Eiferman RA, Carothers DJ, Yankeelov JA. Peripheral rheumatoid ulceration and evidence for conjunctival collagenase production. Am J Ophthalmol 1979;87:703-9.

38 Brown SI, Weller CA, Wasserman HE. Collagenolytic activity of alkali burned corneas. Arch Ophthalmol 1969;81:370-6.

39 Berman M, Leary R, Gage J. Latent collagenase in the ulcerating rabbit cornea. Exp Eye Res 1977;25:435-55.

40 Girard MT, Matsubara M, Fini ME. Transforming growth factor-beta and interleukin-1 modulate metalloproteinase expression by corneal stromal cells. Invest Ophthalmol Vis Sci 1991:32:2441-54.

41 Girard MT, Matsubara M, Kublin C, et al. Stromal fibroblasts synthesise collagenase and stromelysin during long term tissue remodeling. J Cell Sci 1993; 104:1001-11. 